\title{
Experimental and numerical study of pool fire dynamics in an air-tight compartment focusing on pressure variation
}

\author{
Junyi Li ${ }^{\mathrm{a}, *}$, Tarek Beji ${ }^{\mathrm{a}}$, Sylvain Brohez ${ }^{\mathrm{b}}$, Bart Merci ${ }^{\mathrm{a}}$ \\ a Ghent University, Department of Structural Engineering and Building Materials, Ghent, Belgium \\ ${ }^{\mathrm{b}}$ University of Mons, Département de Génie des Procédés Chimiques, Mons, Belgium
}

\section{A R T I C LE IN F O}

\section{Keywords}

Air-tight compartment fire

Pool fire

Pressure variation

Leakage estimation

CFD modeling

\begin{abstract}
A B S T R A C T
The present paper studies the fire-induced pressure evolution in an air-tight compartment. Two cases with different sizes (i.e., $0.3 \mathrm{~m} \times 0.3 \mathrm{~m}$ and $0.5 \mathrm{~m} \times 0.5 \mathrm{~m}$ ) of square methanol pool fire are considered. Repeated tests were performed for each case, leading to a total of four fire experiments. The leakage of the compartment is measured under different pressure conditions in order to obtain the relationship between the leakage and the pressure increase. The pressure inside the compartment reaches peak values of $133 \mathrm{~Pa}$ and $697 \mathrm{~Pa}$ for the small and the large pool fire, respectively. Simulation results using the Fire Dynamics Simulator (FDS) 6.5.3 match well with experiments. The simulated leakage flow rates, which reach values up to $65 \mathrm{~m}^{3} / \mathrm{h}$ and $200 \mathrm{~m}^{3} / \mathrm{h}$, respectively, depend on the pressure variation and leakage settings. The pressure rises strongly in the growth phase of the fire, in line with a rapid increase in fire heat release rate. The gradually increasing heat losses subsequently lead to a decrease in pressure.
\end{abstract}

\section{Introduction}

With the increasing need to reduce energy consumption, more and more energy efficient buildings are designed. The annual energy demand of an air-tight low-energy house is $75-95 \%$ lower than that of a traditional insulated building of the same geometry [1]. The airtightness, which is a main feature of the low-energy buildings, reduces the uncontrollable air exchange between indoors and outdoors, thereby decreasing the energy demand needed to maintain the indoor environment at a stable level. Besides, the building façade needs to be sealed in tropical regions in order to prevent the rainstorm water pushed by wind from leaking to the indoor area [2]. Applications of air-tight buildings can also be found in the nuclear industry, aiming to avoid the potential release of radioactive material to the outside [3]. However, from the standpoint of fire safety, the airtightness will introduce new fire risks. The low leakage will prevent the hot combustion fumes from flowing out of the building and lead to a high pressure rise inside the room.

Fire dynamics in air-tight buildings has drawn attention from the fire safety community. Experimental studies showed substantial fire-induced pressure rise, reaching thousands of Pascal, in air-tight compartments [4-9]. Additionally, part of the construction was destroyed in one of the campaigns in Ref. [5] because of the high pressure. The results illustrated that the pressure rise is an important issue to be considered in air-tight compartment fires. The over-pressures were also reported in simulation results $[4,5,7-11]$, which match well with experiments. A more detailed summary of fire-induced pressure build-up studies can be found in Ref. [11].
It has been reported that the fire source, ventilation conditions, and compartment properties are the main features affecting pressure build-up during an air-tight compartment fire [3]. A study of the factors affecting pressure rise based on the energy balance is conducted in the present study. Unlike the fire source of wooden slats used in Refs. $[8,9]$, the present work involves liquid fuel (i.e., methanol), for which it is easier to determine the heat release rate (HRR) and to be modelled in the simulations. Although ventilation systems are normally mounted in an air-tight residential building to mechanically renew the indoor air, the present study does not include mechanical ventilation, but rather focuses on the leakage. Sinai [12] modelled compartment fires using the Computational Fluid Dynamics (CFD) solver CFX. The comparison between numerical and experimental results showed that fires are very sensitive to leakage in weakly ventilated buildings [12]. More recently, Wahlqvist et al. [13] simulated compartment fires with the mechanical ventilation system using FDS 6.1.1 and pointed out that setting the leakage correctly can be vital in the simulation. A standard procedure to determine the leakage settings is proposed in ASTM E779-10 [14]. The compartment leakage settings of the present study were determined following the procedure in Ref. [14], but the pressure range was extended to more than $400 \mathrm{~Pa}$. This could give more realistic leakage settings during high over-pressure.

The fire-induced high over-pressure can block inward-opening doors, thus obstructing evacuation [15]. It is reported that an over-pressure of more than $100 \mathrm{~Pa}$ can prevent the occupants from evacuating during a fire $[4,16,17]$ and the breakage of the structure may occur when the inside pressure reaches up to around 1500-3000 Pa [13]. This confirms that the pressure build-up by fires in air-tight build-

\footnotetext{
* Corresponding author. 
ings deserves attention, and motivates the present study on fire-induced pressure variation in a compartment with a very low leakage. It is expected to give more insights into the fire-induced pressure rise and numerical modeling of the pressure, as well as to raise attention in considering this potential problem during fire safety design.

\section{Experimental set-up}

\subsection{Geometry of the compartment}

The experimental facility, located in Mons (Belgium), consists of two rooms separated by a $0.12 \mathrm{~m}$ thick partition wall [8]. The sketch of the compartment is shown in Fig. 1. The inner dimensions of the compartment are $12.12 \mathrm{~m} \times 2.4 \mathrm{~m} \times 2.4 \mathrm{~m}$. The larger room $(8 \mathrm{~m}$ in length) is used as a fire room and is connected to the adjacent room through a $2 \mathrm{~m} \times 0.9 \mathrm{~m} \times 0.04 \mathrm{~m}$ door. The outer door has the same dimensions as the partition door and both were closed during the fire tests. The outer door was well-sealed while the partition door has a $0.90 \mathrm{~m} \times 0.01 \mathrm{~m}$ gap at the bottom [8]. The pressure measurement probes are mounted on the side wall in the compartment as shown in Fig. 1.

\subsection{Boundary conditions}

The outer walls are composed of three layers from the inside to the outside [8]: $0.026 \mathrm{~m}$ plaster board, $0.05 \mathrm{~m}$ mineral wool insulation and $0.2 \mathrm{~m}$ concrete brick. The ceiling and floor are made of $0.15 \mathrm{~m}$ concrete slab, but only the ceiling is insulated (with $0.013 \mathrm{~m}$ plaster boards and $0.05 \mathrm{~m}$ mineral wool). The partition wall consists of two layers of plaster boards with mineral wool in between. The two doors are composed of polyurethane foam, covered with galvanized steel on both sides. The material properties are taken from Ref. [17] and listed in Table 1.

\subsection{Case description}

Two cases, with different fire sizes, are considered in the present paper. The fire source used in the experiments is methanol, placed in a square fuel pan made of steel. Two pan sizes are used: $0.3 \mathrm{~m} \times 0.3 \mathrm{~m}$ and $0.5 \mathrm{~m} \times 0.5 \mathrm{~m}$. The pan height is about $3 \mathrm{~cm}$. For the small and the large pool fire, the volumes of methanol are $1.3 \mathrm{~L}$ and $3.3 \mathrm{~L}$, respectively, to have a fire duration of about $10 \mathrm{~min}$. The center of the fuel pan is about $1.43 \mathrm{~m}$ from the back wall and $1.2 \mathrm{~m}$ from the side walls, see Fig. 1. A scale, with an accuracy of $10 \mathrm{~g}$, was placed underneath the fuel pan to measure the mass every second. Each case was conducted twice to evaluate the repeatability of the experiments.

\subsection{Fan pressurization test}

In order to determine the leakage of the compartment, a fan pressurization test was conducted according to the procedure described in ASTM E779-10 [14]. The relationship between the leakage flow and the pressure rise can be determined based on measurements over a range of $0-100 \mathrm{~Pa}$. It is worth noting that the test is not strictly following the standard pressure range of 0-100 $\mathrm{Pa}$. As the pressure could reach hundreds of Pascal during the fire, the fan pressurization test here also considers pressures higher than $100 \mathrm{~Pa}$ (i.e., more than $400 \mathrm{~Pa}$ ). The air was blown into the compartment through a duct linked to the side wall of the smaller room, as shown in Fig. 1. According to the ASTM E779-10, two places can be considered as one single-zone if the pressure difference between the two places is no more than $5 \%$ of the inside to outside pressure difference, and the partition door should be open during the test so that the compartment can be treated as a single-zone building. Since the partition door was closed in the fire tests to investigate the pressure difference between the two rooms, both the partition door open ('PDO') and partition door closed ('PDC') conditions were tested in the fan pressurization test.

\section{Numerical modeling}

Numerical studies have been carried out by using the Fire Dynamics Simulator (FDS) version 6.5.3 [18]. The numerical model was built based on the experimental setups as described above. The default settings of FDS were used in the simulations, unless specified otherwise.

\subsection{Fire source}

The small and large methanol pool fire source is represented in the simulations by a $0.3 \mathrm{~m} \times 0.3 \mathrm{~m} \times 0.1 \mathrm{~m}$ and a $0.5 \mathrm{~m} \times 0.5 \mathrm{~m} \times 0.1 \mathrm{~m}$ obstruction, respectively. The mass loss rate was prescribed based on the experimental results. The mass was recorded at a sampling frequency of $1 \mathrm{~s}$ in the experiments. The experimental mass losses as a function of time for both cases are shown in Fig. 2. The mass $(\mathrm{m})$ is divided by the initial mass $\left(\mathrm{m}_{\text {init }}\right)$ to elimi-

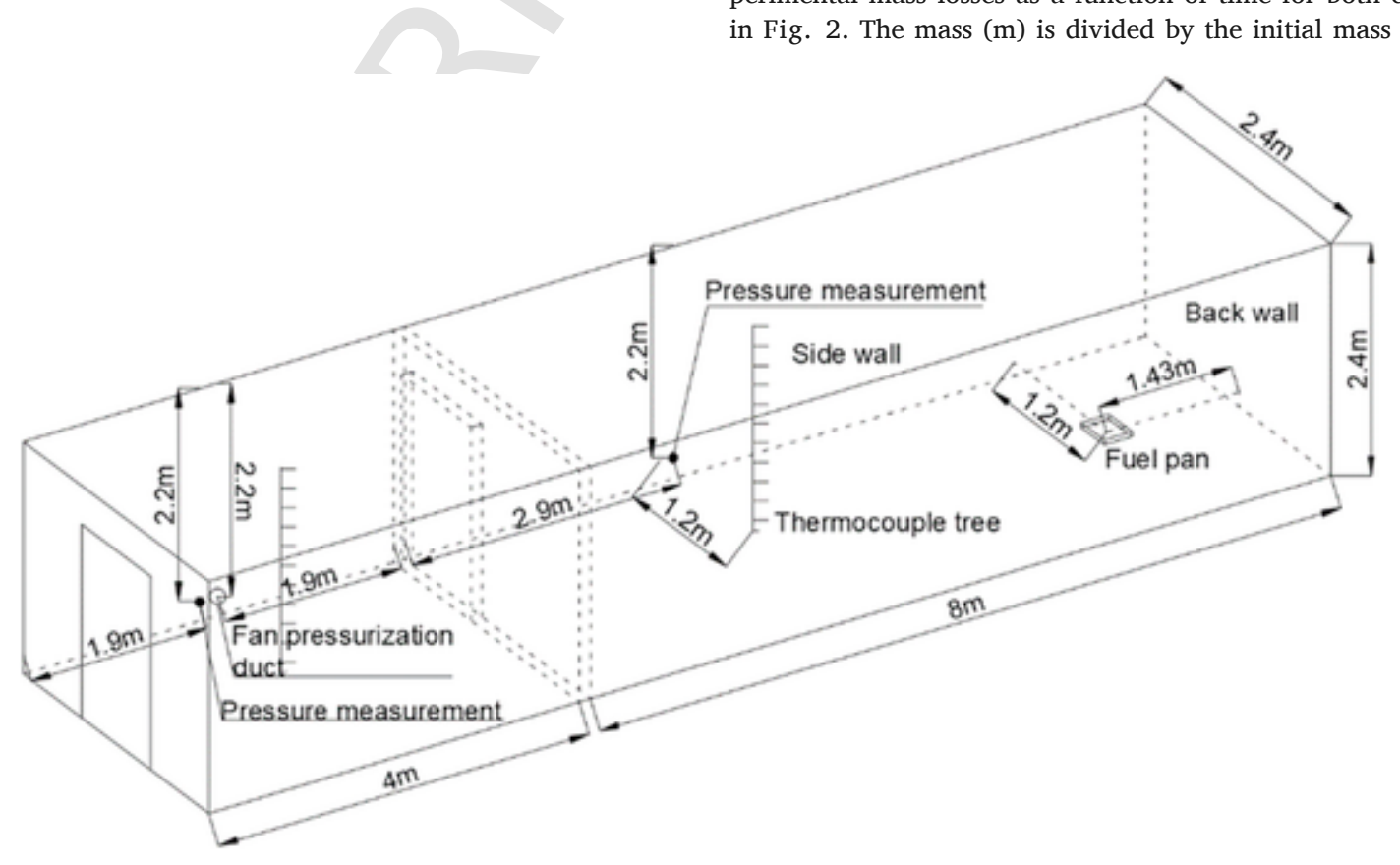

Fig. 1. Sketch of the experimental facility. 
Table 1

Thermal properties of boundary materials.

\begin{tabular}{|c|c|c|c|}
\hline Material & $\begin{array}{l}\text { Density (kg/ } \\
\left.\mathrm{m}^{3}\right)\end{array}$ & $\begin{array}{l}\text { Conductivity } \\
(\mathrm{W} /(\mathrm{m} \cdot \mathrm{K}))\end{array}$ & $\begin{array}{l}\text { Specific heat } \\
(\mathrm{kJ} /(\mathrm{kg} \cdot \mathrm{K}))\end{array}$ \\
\hline Concrete & 2200 & 1.100 & 0.88 \\
\hline Brick & 1600 & 0.690 & 0.84 \\
\hline $\begin{array}{l}\text { Mineral } \\
\text { wool }\end{array}$ & 100 & 0.041 & 0.80 \\
\hline Gypsum & 1440 & 0.480 & 0.84 \\
\hline Foam & 800 & 0.028 & 1.45 \\
\hline Steel & 7850 & 45.800 & 0.46 \\
\hline
\end{tabular}

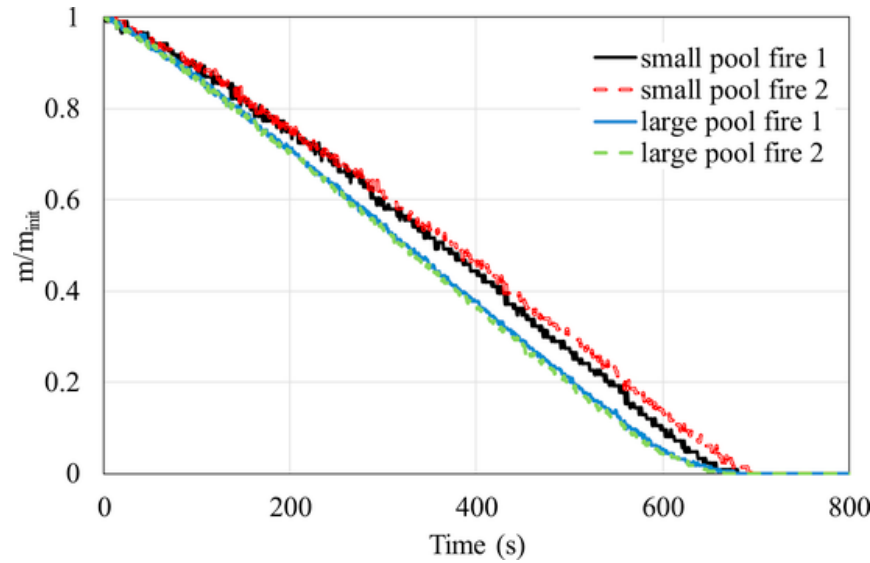

Fig. 2. Fuel mass over initial mass as function of time.

nate the differences in initial mass. The initial masses are listed in Table 2. It can be seen that there is a good repeatability for the mass profiles. As expected, the normalized mass loss rate is somewhat faster for the larger fire area. The average mass of the duplicate cases is used to calculate the mass loss rate (MLR). The slope of the mass curve was calculated based on every 10 sampling points and was used to represent the mass loss rate, see the dashed lines in Fig. 3. The low accuracy of the scale results in severe fluctuations of the mass loss rate. In order to

Table 2

Initial mass of each case.

\begin{tabular}{lllll}
\hline Case & $\begin{array}{l}\text { Small pool } \\
\text { fire 1 }\end{array}$ & $\begin{array}{l}\text { Small pool } \\
\text { fire 2 }\end{array}$ & $\begin{array}{l}\text { Large pool } \\
\text { fire 1 }\end{array}$ & $\begin{array}{l}\text { Large pool } \\
\text { fire 2 }\end{array}$ \\
\hline $\begin{array}{l}\text { Initial mass } \\
(\mathrm{g})\end{array}$ & 986 & 1024 & 2692 & 2682 \\
\hline
\end{tabular}

get a smooth MLR curve, a logarithmic fitting was carried out for the growth and quasi-steady stages, and a moving average of 20 sampling points was calculated at the decay stage. The fitting curves of the mass loss rate for the small pool fire and large pool fire shown in Fig. 3 are prescribed in the FDS simulations.

\subsection{Mesh cell size}

The choice of the mesh cell size is crucial to obtain a balance between accuracy and computational cost. The required mesh cell size was first estimated using the $D^{*}$ criterion [18]. For simulations involving buoyant plumes, a measure of how well the flow field is resolved is given by the non-dimensional expression $D^{*} / \delta x$, which is recommended to be between 5 and 10 [19], where $\delta x$ is the cell size and $D^{*}$ is the characteristic fire diameter. The characteristic diameters for small and large pool fire cases are calculated based on the maximum HRR during the quasi-steady state, i.e., $32 \mathrm{~kW}$ for the small pool fire and $92 \mathrm{~kW}$ for the large pool fire. Thus, the recommended ranges of cell size for the small pool fire case and the large pool fire case are $2.4 \mathrm{~cm}-4.9 \mathrm{~cm}$ and $3.7 \mathrm{~cm}-7.4 \mathrm{~cm}$, respectively. Simulations with different cubic cell sizes (i.e., $1.25 \mathrm{~cm}, 2.5 \mathrm{~cm}$ and $5 \mathrm{~cm}$ ) are conducted to assess the sensitivity of the results to the cell size. It is noted that, for simulations with cell sizes of $2.5 \mathrm{~cm}(1.25 \mathrm{~cm}$, respectively), only the region around the fire is refined to $2.5 \mathrm{~cm}(1.25 \mathrm{~cm}$, respectively), while the remainder of the computational region has a cell size of $5 \mathrm{~cm}(2.5 \mathrm{~cm}$, respectively). The refined region spans from $1 \mathrm{~m}$ from the back wall to $2 \mathrm{~m}$ from the back wall. The non-uniform cell size is used to save the computational time. The results with different cell sizes are shown in Fig. 4. It can be seen that, for both fires, a cell size of $2.5 \mathrm{~cm}$ around the fire source can yield grid insensitive pressure results. Thus, the following simulation results are based on the cell size of $2.5 \mathrm{~cm}$ around the fire source.

\subsection{Modeling of the leakage}

Two methods are provided in FDS to simulate the flow through narrow leakages, i.e., pressure zone leakage and localized leakage [18]. The pressure zone leakage assumes that the leakage is uniformly distributed over all the solid surfaces assigned the LEAK_PATH inside a specified pressure zone. The localized leakage is used when the exact position and geometry of the leakage are known.

Considering that the leak may grow as small gaps, cracks and other leakage paths open up when the room pressure increases [18], the leakage can be calculated based on the pressure difference and the leakage pressure exponent. The settings of the leakage pressure exponent and the reference pressure difference depend on the calculation of the leakage based on experiments, which will be discussed later.
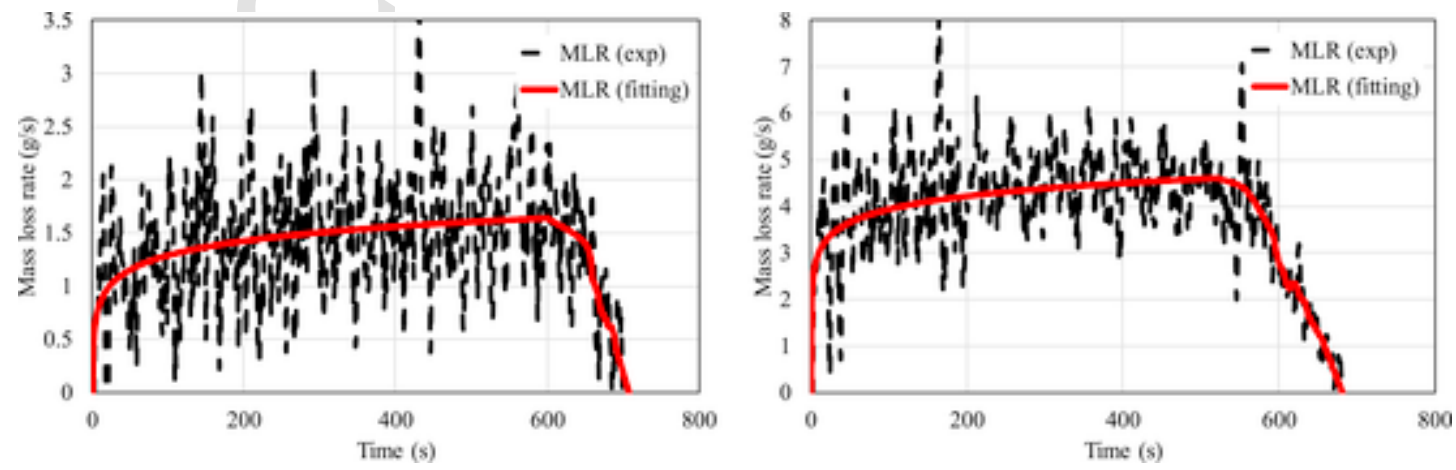

Fig. 3. Mass loss rate for small pool fire (left) and large pool fire (right). 

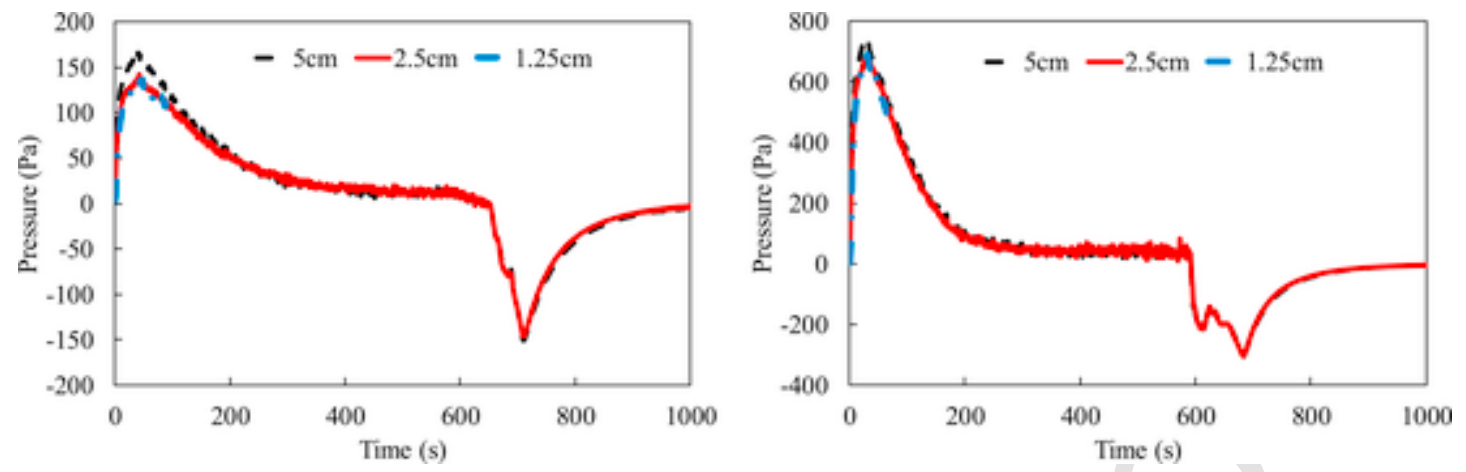

Fig. 4. Simulation results with different cell sizes for small pool fire case (left) and large pool fire case (right).

\section{Results and discussion}

\subsection{Leakage calculation}

During the experimental leakage test without fire, air was blown into the compartment through a duct connected to the adjacent room, which induces and maintains an over-pressure in the compartment. Two leakage tests were considered: one with the partition door closed ('PDC') and another with the partition door open ('PDO'). A sketch of the air flow during the leakage test with the partition door closed is shown in Fig. 5. When the partition door is open, the compartment is treated as one zone, i.e., $P_{a}=P_{f}$. Steady-state conditions are obtained during the measurements.

In the PDC test, the air flows into the adjacent room through the duct, and then flows out through the leakages in the adjacent room and the gap at the bottom of the partition door. For the fire room, the air flows in through the gap at the bottom of the partition door and flows out through the leakages in the fire room. Different stable pressure levels generated by blowing air into the compartment and the blowing flow rates of the air are listed in Table 3. The table also lists the calculated leakage flow rate (through the gap under the partition door) based on the pressure difference between the fire room and the adjacent room.

The air flow rate in the inlet duct is measured and the air flow rate through the gap can be calculated based on the pressure difference between the two rooms and the adjacent room air density:

$\dot{V}_{g a p, a}=C_{d} A_{\text {gap }} \sqrt{\frac{2\left(P_{a}-P_{f}\right)}{\rho_{a}}}$

where $\dot{V}_{\text {gap }, a}$ is the calculated volume flow rate $\left(\mathrm{m}^{3} / \mathrm{s}\right)$ through the gap at the bottom of the partition door based on the adjacent room air density, see Table $3, C_{d}$ is the discharge coefficient (set to 0.7 for a gap under a door [17]), $A_{g a p}$ is the gap area $\left(\mathrm{m}^{2}\right), P_{a}$ and $P_{f}(\mathrm{~Pa})$ are the pressure in the adjacent room and the fire room, respectively, and $\rho_{a}$ is the adjacent room air density $\left(\mathrm{kg} / \mathrm{m}^{3}\right)$. The calculation of air density is based on the indoor temperature $\left(T,{ }^{\circ} \mathrm{C}\right)$ and the elevation above sea level $(E, \mathrm{~m})[14]$ :

$$
\rho=1.2041\left(1-\frac{0.0065 \cdot E}{293}\right)^{5.2553}\left(\frac{293}{T+273}\right)
$$

The elevation of the present experimental site obtained from the meteorological station is $60 \mathrm{~m}$. The leakage calculation is based on the procedure proposed in ASTM E779-10 [14]. In order to express all the volumetric flow rates based on the indoor conditions, the readings of the measured inlet air flow rate are converted into volumetric air flows at the temperature and barometric pressure of the inside air for pressurization tests [14]:

$\dot{V}_{\text {in }}=\dot{V}_{\text {in, measured }} \cdot\left(\frac{\rho_{\text {out }}}{\rho_{\text {in }}}\right)$

where $\dot{V}_{\text {in }}$ is the converted inlet volume flow rate $\left(\mathrm{m}^{3} / \mathrm{s}\right), \dot{V}_{\text {in,measured }}$ is the measured inlet volume flow rate $\left(\mathrm{m}^{3} / \mathrm{s}\right), \rho_{\text {out }}$ is the outdoor air density $\left(\mathrm{kg} / \mathrm{m}^{3}\right)$ and $\rho_{\text {in }}$ is the indoor air density $\left(\mathrm{kg} / \mathrm{m}^{3}\right)$.

For the adjacent room, $\rho_{i n}=\rho_{a}$, and the leakage flow rate $\left(\dot{V}_{\text {leak }, a}\right.$, $\mathrm{m}^{3} / \mathrm{s}$ ) can be calculated:

$\dot{V}_{\text {leak }, a}=\dot{V}_{\text {in }}-\dot{V}_{\text {gap }, a}$

A log-log plot of the leakage flow rate against the adjacent room pressure can be obtained, see Fig. 6, assuming a power law expression [20]:

$\dot{V}_{\text {leak }, a}=C \cdot(\Delta p)^{n}$

where $\Delta p(\mathrm{~Pa})$ is the pressure difference between the inside and the outside. For the adjacent room, $\Delta p=P_{a}$ (see Table 3). The plotted data in Fig. 6 can be used to determine the coefficient $C$ and the pressure exponent $n$. The coefficient $C$ needs to be corrected to standard conditions $\left(20{ }^{\circ} \mathrm{C}\right.$ and sea level $E=0 \mathrm{~m}$ ) [14]:

$C_{s t}=C\left(\frac{\mu}{\mu_{0}}\right)^{2 n-1}\left(\frac{\rho}{\rho_{0}}\right)^{1-n}$

where $C_{s t}\left(\mathrm{~m}^{3} / \mathrm{s} \cdot \mathrm{Pa}^{\mathrm{n}}\right)$ is the corrected coefficient at standard conditions, $\mu$ and $\mu_{0}(\mathrm{~kg} / \mathrm{m} \cdot \mathrm{s})$ are the dynamic viscosity of air at the indoor condition and the standard condition, respectively, $\rho$ and $\rho_{0}\left(\mathrm{~kg} / \mathrm{m}^{3}\right)$ are

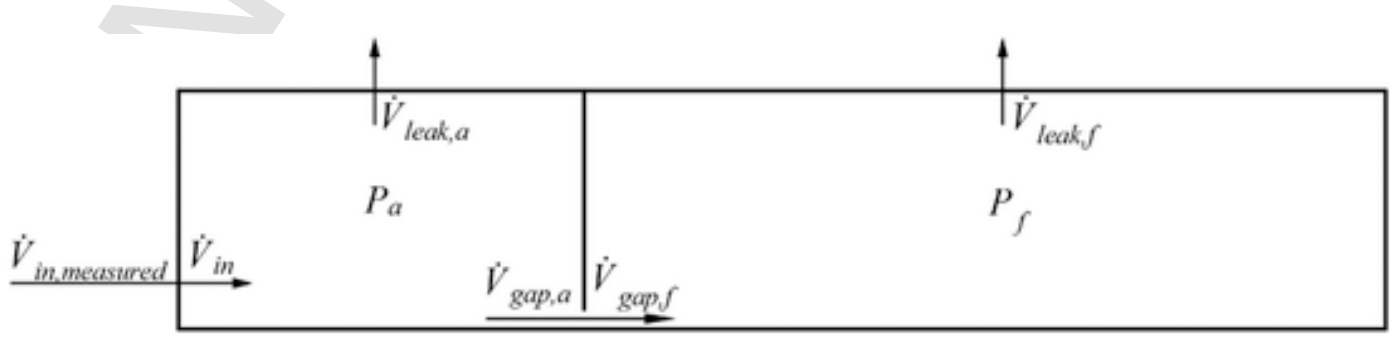

Fig. 5. Air flow during the leakage test. 
Table 3

Pressurization data points for the PDC case.

\begin{tabular}{lllllll}
\hline Point & $P_{a}(\mathrm{~Pa})$ & $P_{f}(\mathrm{~Pa})$ & $\begin{array}{l}\dot{V}_{\text {in,measured }} \\
\left(\mathrm{m}^{3} / \mathrm{s}\right)\end{array}$ & $\begin{array}{l}\dot{V}_{\text {in }} \\
\left(\mathrm{m}^{3} / \mathrm{s}\right)\end{array}$ & $\begin{array}{l}\dot{V}_{\text {gap, } a} \\
\left(\mathrm{~m}^{3} / \mathrm{s}\right)\end{array}$ & $\begin{array}{l}\dot{V}_{\text {gap } f} \\
\left(\mathrm{~m}^{3} / \mathrm{s}\right)\end{array}$ \\
\hline 1 & 445.36 & 429.13 & 0.0723 & 0.0742 & 0.0319 & 0.0322 \\
2 & 420.92 & 405.70 & 0.0697 & 0.0715 & 0.0308 & 0.0312 \\
3 & 372.93 & 359.91 & 0.0633 & 0.0649 & 0.0285 & 0.0288 \\
4 & 240.38 & 233.97 & 0.0475 & 0.0487 & 0.0200 & 0.0202 \\
5 & 130.38 & 127.76 & 0.0303 & 0.0311 & 0.0128 & 0.0129 \\
6 & 82.62 & 81.27 & 0.0220 & 0.0226 & 0.0092 & 0.0093 \\
7 & 64.94 & 63.99 & 0.0185 & 0.0190 & 0.0077 & 0.0078 \\
\hline
\end{tabular}

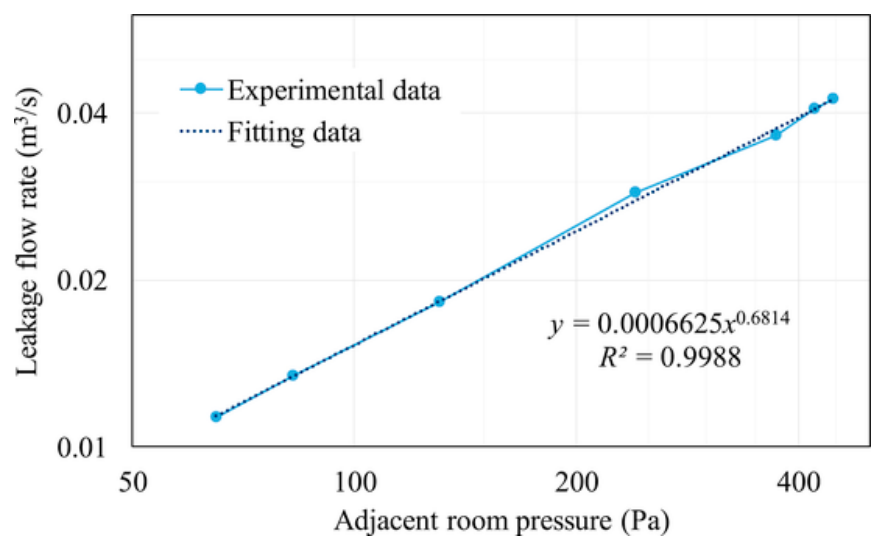

Fig. 6. Log-log plot of leakage flow rate against the adjacent room pressure.

the air density at the indoor condition and the standard condition, respectively. The calculation of dynamic viscosity is based on the indoor temperature $\left(T,{ }^{\circ} \mathrm{C}\right)[14]$ :

$\mu=\frac{b(T+273)^{0.5}}{1+s /(T+273)}$

where $b=1.458 \times 10^{-6} \mathrm{~kg} /\left(\mathrm{m} \cdot \mathrm{s} \cdot \mathrm{K}^{0.5}\right)$ and $s=110.4 \mathrm{~K}$.

The obtained values of $C$ and $n$ are 0.0006625 and 0.6814 , respectively, using a power fitting technique with $R^{2}=0.9988$, see Fig. 6 . The corrected coefficient at standard conditions $C_{s t}$ is 0.0006622 .

For the sake of completeness, it is mentioned that the corrections on air density, coefficient $C$ and viscosity, are very small in the case at hand. Nevertheless, the standard procedure has been applied (as it should be conducted as well for experiments in more extreme conditions, such as a plateau with very high elevation).

The volume flow rate through a leakage is computed in FDS using a typical orifice flow formula $[18,21]$ :

$\dot{V}_{\text {leak }, a}=C_{d} A_{L} \sqrt{\frac{2 \Delta p}{\rho_{0}}}$

where $C_{d}$ is the discharge coefficient, $A_{L}$ is the leakage area $\left(\mathrm{m}^{2}\right)$. Substituting Eq. (8) into Eq. (5), the leakage area can be calculated from the corrected leakage coefficient and the pressure exponent using a reference pressure difference $\left(\Delta p_{\text {ref }}, \mathrm{Pa}\right)$ :

$A_{L}=\frac{C_{s t}}{C_{d}}\left(\frac{\rho_{0}}{2}\right)^{\frac{1}{2}}\left(\Delta p_{r e f}\right)\left(n-\frac{1}{2}\right)$

The leakage area $\left(A_{L}\right)$, reference pressure difference $\left(\Delta p_{\text {ref }}\right)$ and leakage pressure exponent $(n)$ are input parameters in FDS (ZONE namelist group) to simulate the leak flow. In the ASTM standard and FDS, the discharge coefficient $\left(C_{d}\right)$ seen in this formula is assumed to be $1[14,18]$. It is noted that combining Eqs. (8) and (9) leads to a relation of the form of Eq. (5).

The same procedure is used to calculate the leakage area in the fire room (PDC) and the leakage area in the PDO case. For the leakage calculation of the fire room, $\Delta p$ represents the fire room pressure $P_{f}$ and the volume flow rate through the gap at the bottom of the partition door based on the fire room air density $\left(\dot{V}_{\text {gap } f}, \mathrm{~m}^{3} / \mathrm{s}\right)$ can be calculated:

$\dot{V}_{\text {gap } f}=\dot{V}_{g a p, a} \cdot\left(\frac{\rho_{a}}{\rho_{f}}\right)$

where $\rho_{f}$ is the fire room air density $\left(\mathrm{kg} / \mathrm{m}^{3}\right)$ calculated with Eq. (2). The gap volume flow rates are listed in Table 3. For the leakage calculation of the PDO case, the whole compartment was treated as one single zone. The converted inlet flow rate measurements were used as net inward volume flow rates and the pressure inside the compartment was used as the pressure difference. The calculated values of the leakage area and the leakage pressure exponent at a reference pressure difference of $50 \mathrm{~Pa}$ for both cases are listed in Table 4. Although the outer door in the adjacent room was sealed, leakage paths may open up when the inside pressure increases, and there is no opening in the fire room, except for the gap under the partition door, which leads to a larger leakage area in the adjacent room than that in the fire room. The sum of the leakage area in the adjacent room and the fire room for the PDC case is $17.43 \mathrm{~cm}^{2}$, which is very close to the leakage area of the PDO case $\left(17.73 \mathrm{~cm}^{2}\right)$. Moreover, the pressure exponent of the PDO case is in between the values of the adjacent room and the fire room for the PDC case. This indicates that closing the partition door has little influence on the leakage area, but has some effect on the pressure exponent.

Since the partition door was closed during the fire tests, the values of the PDC case were used in the fire simulations. The air leakage from the compartment to the ambient is simulated using the pressure zone leakage approach, because the exact locations of the leakages are unknown. The walls and ceiling are set as leak path. Since the partition door was closed during the experiment, two pressure zones (one for each room) are prescribed in FDS, in addition to the ambient pressure zone. Besides, the gap at the bottom of the partition door is defined as a localized leakage.

\subsection{Fire test pressure variation}

The pressure variations as function of time are shown in Fig. 7. The dashed lines refer to the mean value of pressure for the two duplicate tests and the bars indicate the discrepancy between the tests. For the small pool fire case, larger discrepancies are observed during the under-pressure period because one of the tests has slightly less fuel, which leads to earlier burning out and occurrence of the under-pressure. Although there are discrepancies between the pressure curves because of different fuel mass, the magnitude and trend of the pressures are very similar for both tests. It can be seen from Fig. 7 that, with the fire development, the indoor pressure increases substantially, reaching a peak value of $133 \mathrm{~Pa}$ for the small pool fire and $697 \mathrm{~Pa}$ for the large

Table 4

Calculated values of leakage area and pressure exponent.

\begin{tabular}{llll}
\hline Parameter & Partition door closed (PDC) & Partition door open (PDO) \\
\hline & Adjacent room & $\begin{array}{l}\text { Fire } \\
\text { room }\end{array}$ \\
\hline Leakage area $\left(\mathrm{cm}^{2}\right)$ & 10.45 & 6.98 & 17.73 \\
Pressure exponent & 0.681 & 0.753 & 0.738 \\
\hline
\end{tabular}



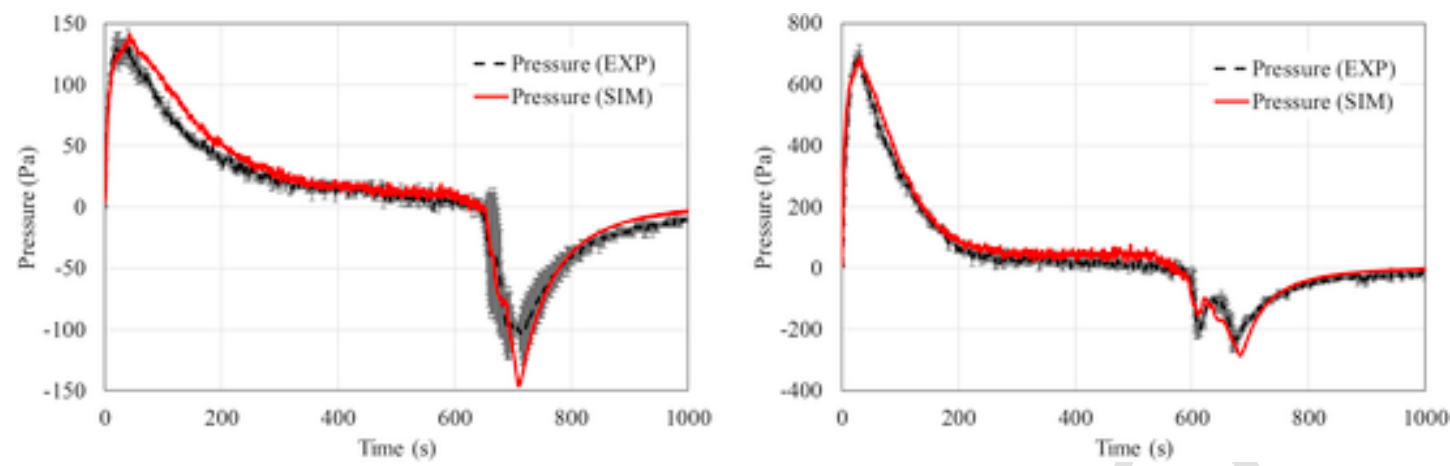

Fig. 7. Pressure variation as function of time for the small pool fire (left) and the large pool fire (right).

pool fire, before decreasing gradually to near-zero. When the fuel is about to burn out, the heat released from the fire decreases, resulting in an under-pressure in the compartment. Fig. 7 shows that the overall trend and magnitude of the pressure profiles are well captured in the FDS simulations. Nevertheless, over-predictions are observed after the over-pressure peak and during the under-pressure period. The first reason for these over-predictions could be related to the uncertainty in the mass measurements. As mentioned above, the accuracy of the scale is about $10 \mathrm{~g}$, so the mass loss rates of the fuel may not be very accurate, especially for the small pool fire. This could have a significant influence on the pressure build-up, as discussed in section 4.4. Besides, the over-predictions of the pressure after the over-pressure peak could be due to an under-estimation of the heat losses in the simulations, considering the energy balance shown below in Eq. (12). Moreover, the leakage area and leakage pressure exponent used in the simulations, which affect the pressure prediction, are the same in the over-pressure period and under-pressure period, whereas it has been reported in Refs. $[5,14]$ that this is not necessarily the case. In practice, the peak pressure and duration of pressure higher than a critical value (e.g., $100 \mathrm{~Pa}$ ) that may prevent evacuation, should be the main considerations in fire safety design. It can be seen from Table 5 that the over-pressure peaks are well-reproduced in the simulations while the under-pressure peaks

Table 5

Discrepancy between experimental and numerical results.

\begin{tabular}{lllll}
\hline & \multicolumn{2}{l}{ Over-pressure peak } & \multicolumn{2}{l}{ Under-pressure peak } \\
\hline & $\begin{array}{l}\text { Small pool } \\
\text { fire }\end{array}$ & $\begin{array}{l}\text { Large pool } \\
\text { fire }\end{array}$ & $\begin{array}{l}\text { Small pool } \\
\text { fire }\end{array}$ & $\begin{array}{l}\text { Large pool } \\
\text { fire }\end{array}$ \\
\hline $\begin{array}{l}\text { Experimental value } \\
\text { (Pa) }\end{array}$ & 133.03 & 696.77 & -104.47 & -235.62 \\
$\begin{array}{l}\text { Numerical value } \\
\text { (Pa) }\end{array}$ & 141.69 & 685.82 & -146.26 & -286.83 \\
Discrepancy (\%) & 6.51 & 1.57 & 40.00 & 21.73 \\
\hline
\end{tabular}

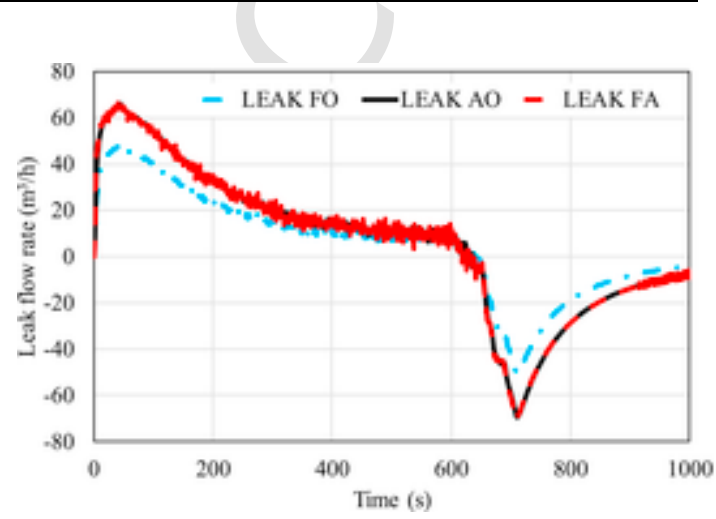

have larger discrepancies. The experimental durations of pressure higher than $100 \mathrm{~Pa}$ are $69 \mathrm{~s}$ and $176 \mathrm{~s}$ for the small pool fire and large pool fire, respectively, while the numerical durations are $94 \mathrm{~s}$ and $182 \mathrm{~s}$, respectively. The discrepancies of the duration for the small pool fire and large pool fire are $36.23 \%$ and $3.4 \%$, respectively.

\subsection{Leakage flow rate}

Although there are no experimental data to validate the numerical results of the leakage flow rates, it is valuable to show this important parameter because it has a significant influence on the pressure variation in an air-tight compartment. The leakage flow rates are shown in Fig. 8, where, the LEAK FO, LEAK AO and LEAK FA indicate the leakage from the fire room to the outside, the leakage from the adjacent room to the outside and the leakage from the fire room to the adjacent room through the gap at the bottom of the partition door, respectively. The leakage flow rate is dependent on the pressure difference and the leakage area [18]:

$\dot{V}_{L}=C_{d} A_{L} \operatorname{sign}(\Delta p) \sqrt{\frac{2|\Delta p|}{\rho_{\infty}}}$

where $\dot{V}_{L}$ is the leakage volume flow rate $\left(\mathrm{m}^{3} / \mathrm{s}\right), A_{L}$ is the leakage area $\left(\mathrm{m}^{2}\right), \Delta p$ is the pressure difference between the adjacent zones ( $\left.\mathrm{Pa}\right)$ and $\rho_{\infty}$ is the ambient air density $\left(\mathrm{kg} / \mathrm{m}^{3}\right)$. Thus, the leakage flow rate has the same trend as the pressure variation. A higher leakage flow rate is observed with the higher pressure rise caused by the larger pool fire. Besides, the leakage flow rate in the fire room is lower than that in the adjacent room because of the smaller leakage area. Moreover, considering the mass conservation in the adjacent room, LEAK FA is similar to LEAK AO. As can be seen from Fig. 8, the leakage flow rate has a relatively high value compared to the mechanical ventilation flow rates (i.e., about $75 \mathrm{~m}^{3} / \mathrm{h}$ ) used in this facility for previous test campaigns [7-9,22]. A maximum leakage flow rate of $65 \mathrm{~m}^{3} / \mathrm{h}$ for the small pool fire case and a maximum leakage flow rate of $200 \mathrm{~m}^{3} / \mathrm{h}$ for the

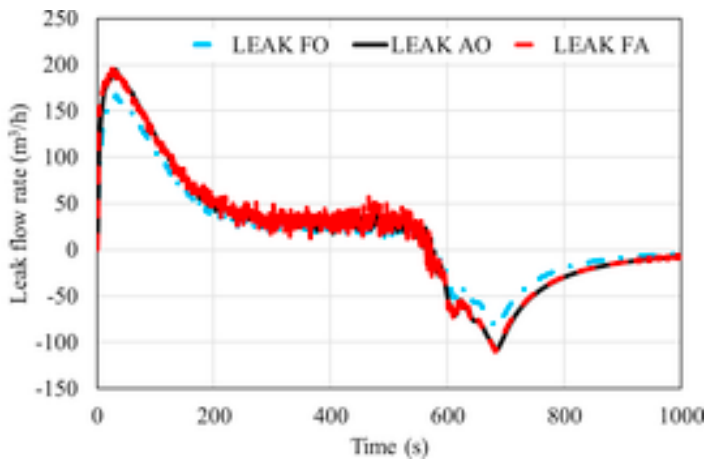

Fig. 8. Leakage flow rates for the small pool fire (left) and the large pool fire (right). 
large pool fire case are obtained. This indicates that the leakage plays an important role in the air-tight compartment ventilation and thus pressure build-up. The modeling of leakage should be essential for air-tight compartment fire simulations, especially without mechanical ventilation. It is worth noting that sharp whistling noises were heard during the experiments, which could be related to the high leakage flow rates.

\subsection{Energy balance analysis}

In an air-tight compartment fire, thermal expansion of the gases caused by the heat release from the fire is limited and thus an increase of pressure is observed inside the compartment. Considering the first law of thermodynamics and low-Mach number fire-induced flows, the energy conservation in an air-tight compartment without mechanical ventilation can be expressed as $[3,17,18]$ :

$\frac{\partial}{\partial t} \int_{C V}\left(\rho h_{s}-p\right) d V=\dot{Q}_{f}-\dot{Q}_{\text {loss }}-\dot{Q}_{\text {leak }}$

where $\rho$ is the gas density $\left(\mathrm{kg} / \mathrm{m}^{3}\right), h_{s}$ is the specific sensible enthalpy $(\mathrm{kJ} / \mathrm{kg}), p$ is the pressure $(\mathrm{Pa}), V$ is the volume of the compartment $\left(\mathrm{m}^{3}\right), \dot{Q}_{f}$ is the fire HRR (kW), $\dot{Q}_{\text {loss }}$ is the heat losses through the walls, floor and ceiling $(\mathrm{kW})$, and $\dot{Q}_{\text {leak }}$ is the heat transfer through the leakage $(\mathrm{kW})$.

According to Eq. (12), for a compartment without mechanical ventilation, the pressure build-up is mainly influenced by the HRR, heat loss rates through the boundary and the leakage flow rate. The output file of FDS simulation includes quantities (e.g., Q_ENTH, Q_PRES, HRR, Q_COND, Q_RADI, and Q_CONV) associated with the overall energy budget [18]. The evolutions of the outputs are shown in Fig. 9. The left hand side (LHS) of Eq. (12) is calculated using outputs of the simu-

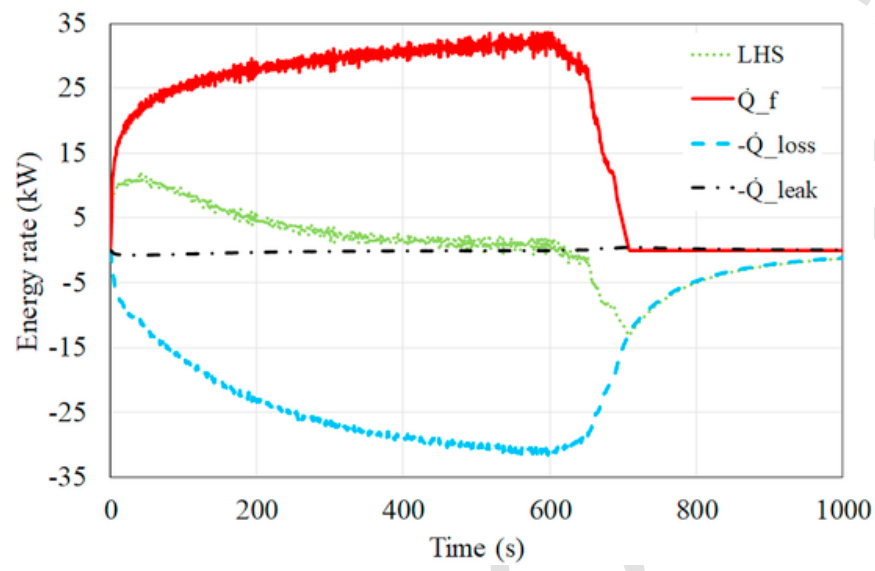

Fig. 9. Temporal evolution of the terms of Eq. (12): left hand side (LHS), $\dot{Q}_{f}$ (Q⿺f), $-\dot{Q}_{\text {loss }}(-\dot{\mathrm{Q}}$ loss $)$ and $-\dot{Q}_{\text {leak }}(-\dot{\mathrm{Q}}$ leak $)$.

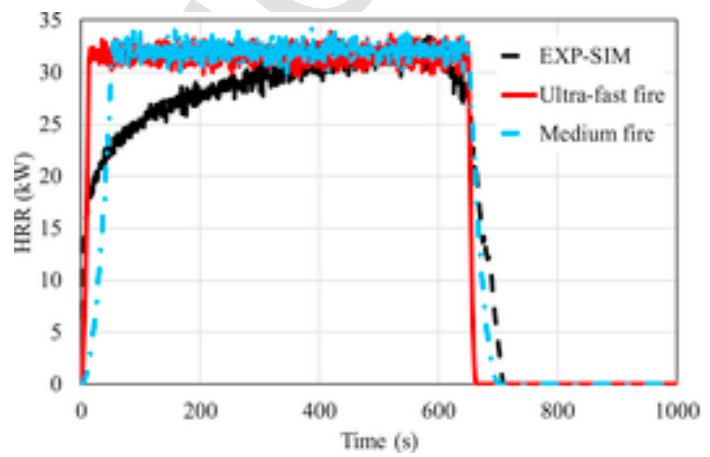

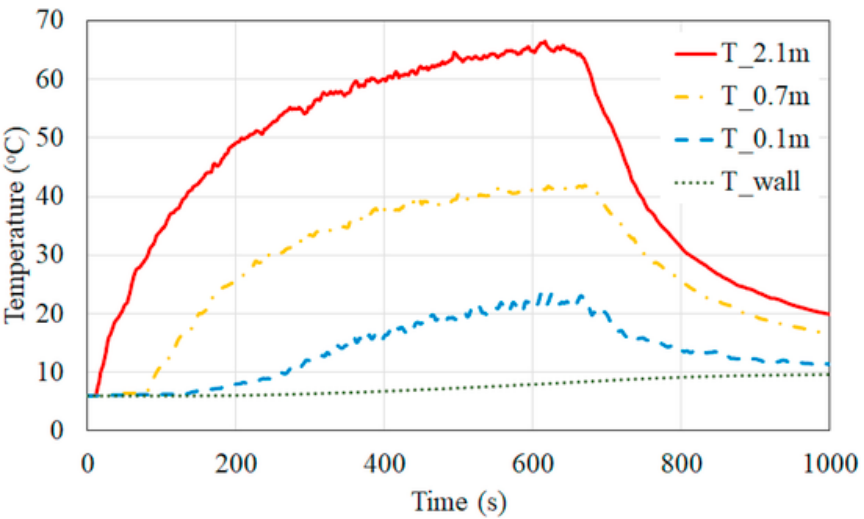

Fig. 10. Gas phase and solid phase temperature evolutions.

lations (i.e., Q_ENTH-Q_PRES). Q_leak is the output of Q_CONV since leakage flow is the only convective flow in the present simulation. Q_loss is considered as the sum of the conductive (Q_COND) and radiative (Q_RADI) heat loss rates.

Fig. 9 shows that, for the air-tight configuration at hand, the small leakage results in low convective heat loss rates through the leak. During the period with substantial pressure rise (i.e., the first $40 \mathrm{~s}$, Fig. 7), the HRR rises much faster than the heat loss rate $\dot{Q}_{\text {loss }}$. This results in the strong pressure build-up. With the temperature gradually rising inside the compartment, the heat loss rate to the boundary, which becomes larger as the indoor temperature rises, increases and catches up with the HRR. Then, the pressure decreases gradually with the increase of heat loss rates. The simulated gas phase temperature $(0.1 \mathrm{~m}, 0.7 \mathrm{~m}$ and $2.1 \mathrm{~m}$ to the floor) and solid phase temperature $(0.6 \mathrm{~m}$ to the floor and $0.012 \mathrm{~m}$ depth in the side wall) are shown in Fig. 10 to aid with the understanding of the variation of heat losses to the boundary. It can be seen that the gas phase temperature increases gradually. The wall temperature rises due to the heat transfer into the walls.

In order to study the influence of HRR evolution on pressure variation, two additional simulations have been carried out, namely with ultra-fast and medium $\mathrm{t}^{2}$ fires. The maximum HRR is set to the same value as the small pool fire case and the decay period is chosen in symmetry with the growth phase, see Fig. 11 (left). Obviously, these scenarios are entirely fictitious, but they serve the purpose of illustrating how the temporal pressure evolution links to the temporal evolution of the HRR. The simulated pressure variations are shown in Fig. 11 (right). The energy terms for $\mathrm{t}^{2}$ fires are shown in Fig. 12. The HRR evolution has a large impact on the pressure build-up. The comparison between the $t^{2}$ fires indicates that the delay in reaching the peak HRR results in the delay of pressure reaching the peak value. The peak value (261 Pa) in the ultra-fast fire is somewhat higher than for the medium fire $(247 \mathrm{~Pa})$, but the values are quite comparable in the current conditions of the simulations. Clearly the HRR is the dominant term on the right hand side of Eq. (12), and the rate of fire HRR increase does

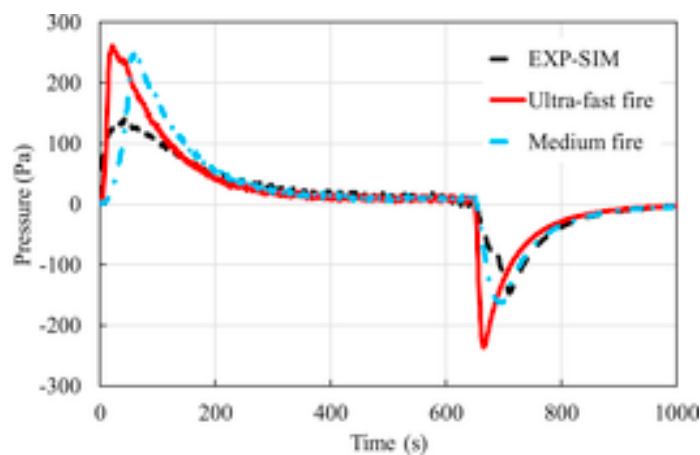

Fig. 11. Different evolutions of HRR (left) lead to different pressure variations (right) 

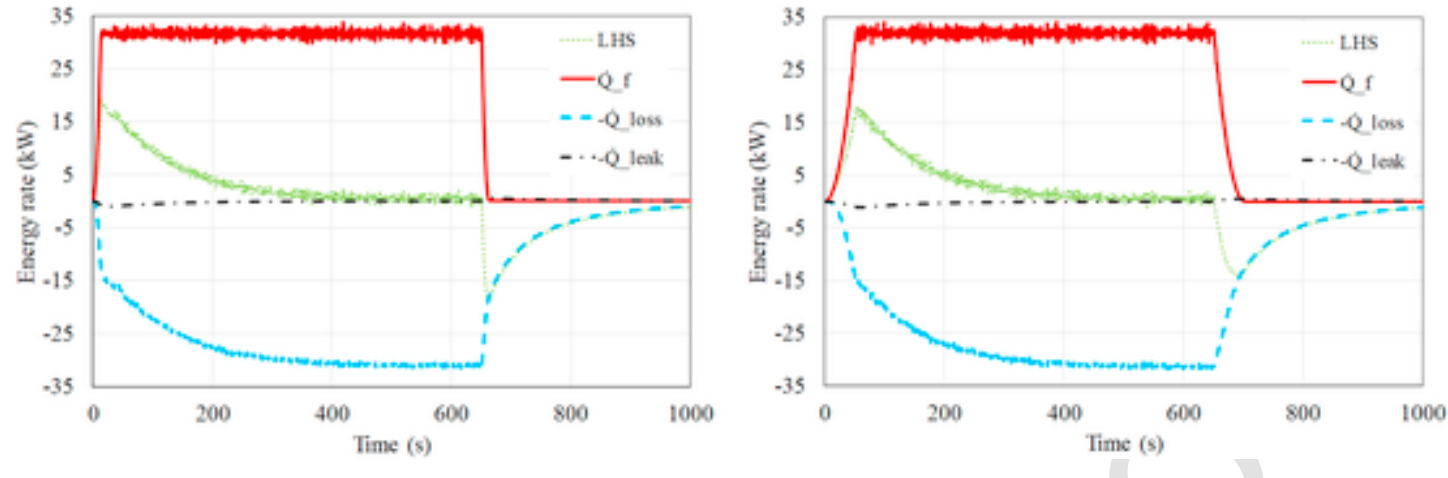

Fig. 12. Temporal evolution of the terms of Eq. (12) for the ultra-fast (left) and medium (right) $\mathrm{t}^{2}$ fire.

not strongly affect the maximum peak value. The pressure reaches the peak value when the HRR reaches a steady value in the fictitious cases, because the heat losses keep increasing, while the HRR remains constant. In the case resembling the experiments, the pressure starts to decrease after $45 \mathrm{~s}$, while the HRR is still clearly increasing (Fig. 11, left), but due to the relatively slower increasing HRR (compared to the fictitious case), the heat losses can keep up with the HRR and this leads to a lower pressure peak value, and to a decrease in pressure despite an increase in HRR. A more detailed analysis of the impact of the energy balance on the pressure evolution will be investigated in future work.

\section{Conclusions}

Methanol pool fire experiments were carried out in an air-tight compartment to study the fire-induced pressure variation. Different fire heat release rates were obtained by using different sizes of fuel pan (i.e., $0.3 \mathrm{~m} \times 0.3 \mathrm{~m}$ and $0.5 \mathrm{~m} \times 0.5 \mathrm{~m}$ ). Numerical simulations with FDS were conducted to reproduce the pressure variations and study the effect of the mass loss rate on pressure rise. The main conclusions are as follows:

The leakage is tested under different pressure conditions and proved to increase with pressure rise. The closing of the partition door has little influence on the leakage area, but has impact on the leakage pressure exponent of the rooms, which could lead to a different growth rate of leakage flow according to the indoor pressure.

The pressure inside the air-tight compartment rises substantially when a fire occurred. The peak values of pressure build-up for the small pool fire case and the large pool fire case are $133 \mathrm{~Pa}$ and $697 \mathrm{~Pa}$, respectively. The simulation results can well reproduce the experimental pressure profiles. The same pressure trends are captured. The discrepancies between experimental and numerical over-pressure (under-pressure) peaks are $6.51 \%(40 \%)$ and $1.57 \%(21.73 \%)$ for the small pool fire and large pool fire, respectively.

The simulated leakage flow rates show a dependency on the pressure variation and leakage settings. The magnitudes of the leakage flow rate reach a maximum of $65 \mathrm{~m}^{3} / \mathrm{h}$ for the small pool fire case and a maximum of $200 \mathrm{~m}^{3} / \mathrm{h}$ for the large pool fire case.

Fictitious $\mathrm{t}^{2}$ fires have been simulated to assess the impact of the fire growth rate on the pressure. The pressure rises strongly in the growth phase of the fire, in line with a rapid increase in fire heat release rate. In the current conditions of simulations, if the rate of increase in fire HRR is (much) faster than the increase in heat losses, it does not have a strong impact on the pressure peak value itself. The gradually increasing heat losses subsequently lead to a decrease in pressure. If the heat losses can keep up with the fire HRR, the peak value for pressure is obtained at a moment where the fire HRR is still increasing, and the peak value is lower than in cases where the heat losses lag behind the fire HRR.

\section{CRediT authorship contribution statement}

Junyi Li: Conceptualization, Methodology, Software, Validation, Formal analysis, Investigation, Writing - original draft, Visualization. Tarek Beji: Conceptualization, Formal analysis, Writing - review \& editing, Supervision. Sylvain Brohez: Investigation, Resources, Writing - review \& editing. Bart Merci: Conceptualization, Formal analysis, Writing - review \& editing, Supervision.

\section{Declaration of competing interest}

The authors declare that they have no known competing financial interests or personal relationships that could have appeared to influence the work reported in this paper.

\section{Acknowledgements}

The authors would like to thank the China Scholarship Council (CSC) for the financial support of Junyi Li (Grant No. 201706420076), as well as the co-funding from Ghent University through BOF (Grant No. 01SC2018). The study is also sponsored by the cross-border PhD mobility grant (Interreg project TRANSUNIV) between UGent and UMons. The authors express sincere words of gratitude to Christophe Lheureux (University of Mons) for his help with the experiments and to Bénédicte Vanwijnsberghe, director of the Régie Provinciale autonome du Hainaut, for the access to the experimental facility.

\section{References}

[1] J Schnieders, W Feist, L Rongen, Passive houses for different climate zones, Energy Build 105 (2015) 71-87, doi:10.1016/j.enbuild.2015.07.032.

[2] W K Chow, G W Zou, Numerical simulation of pressure changes in closed chamber fires, Build. Environ. 44 (2009) 1261-1275, doi:10.1016/j.buildenv.2008.09.016.

[3] H Pretrel, W Le Saux, L Audouin, Pressure variations induced by a pool fire in a well-confined and force-ventilated compartment, Fire Saf. J. 52 (2012) 11-24, doi:10.1016/j.firesaf.2012.04.005

[4] S Hostikka, R K Janardhan, U Riaz, T Sikanen, Fire-induced pressure and smoke spreading in mechanically ventilated buildings with air-tight envelopes, Fire Saf. J. 91 (2017) 380-388, doi:10.1016/j.firesaf.2017.04.006.

[5] R K Janardhan, S Hostikka, Experiments and numerical simulations of pressure effects in apartment fires, Fire Technol. 53 (2017) 1353-1377, doi:10.1007/ s10694-016-0641-z.

[6] L Audouin, L Rigollet, H Pretrel, W Le Saux, M Rowekamp, OECD PRISME project: fires in confined and ventilated nuclear-type multi-compartments - overview and main experimental results, Fire Saf. J. 62 (2013) 80-101, doi:10.1016/ j.firesaf.2013.07.008

[7] S Brohez, I Caravita, Fire induced pressure in passive houses: experiments and FDS validation, Ninth International Seminar on Fire and Explosion Hazards, 2019, pp. 524-533, doi:10.18720/spbpu/2/k19-132.

[8] I Caravita, Fire Development in Passive Houses: Experimental Analysis and Validation of Theoretical Models, Department of civil, chemical, environmenta and materials engineering, Università di Bologna, Bologna, Italy, 2017 Master thesis. 
[9] L Piret-Gérard, Quid Des Dangers Pour Les Occupants Lors D’un Incendie Dans Un Milieu Confiné? Master Thesis, Faculté Polytechnique, Université de Mons, Mons, Belgium, 2017.

[10] F Bonte, N Noterman, B Merci, Computer simulations to study interaction between burning rates and pressure variations in confined enclosure fires, Fire Saf. J. 62 (2013) 125-143, doi:10.1016/j.firesaf.2013.01.030.

[11] J Li, T Beji, S Brohez, B Merci, CFD study of fire-induced pressure variation in a mechanically-ventilated air-tight compartment, Fire Saf. J. (2020) 103012, doi:10.1016/j.firesaf.2020.103012.

[12] Y L Sinai, Comments on the role of leakages in field modelling of under-ventilated compartment fires, Fire Saf. J. 33 (1999) 11-20, doi:10.1016/ S0379-7112(99)00005-3.

[13] J Wahlqvist, P van Hees, Evaluating methods for preventing smoke spread through ventilation systems using fire dynamics simulator, Fire Mater. 41 (2017) 625-645, doi:10.1002/fam.2404.

[14] Astm, Standard test method for determining air leakage rate by fan pressurization (E779-10), Standard Test Method for Determining Air Leakage Rate by Fan Pressurization (E779-10), 2010 United States, doi:10.1520/E0779-10.

[15] S Brohez, P Duhamel, Inwards doors blocked by fire induced overpressure in airtight apartment: a real case in Germany, Chemical Engineering Transactions 67 (2018) 25-30, doi:10.3303/CET1867005.
[16] D Vanhaverbeke, Fire development in passive houses: qualitative description and design of full-scale fire tests, Master Thesis. International Master of Science in Fire Safety Engineering, University of Edinburgh, Edinburgh, 2015.

[17] B Karlsson, Quintiere J, Enclosure Fire Dynamics, CRC press, 1999.

[18] K McGrattan, S Hostikka, R McDermott, J Floyd, C Weinschenk, K Overholt, Fire Dynamics Simulator User's Guide, sixth ed., NIST and VTT., 2017, doi:10.6028/ NIST.SP.1019.

[19] K McGrattan, Verification and validation of selected fire models for nuclear power plant applications volume 7: fire dynamics simulator (FDS), Verification and Validation of Selected Fire Models for Nuclear Power Plant Applications Volume 7: Fire Dynamics Simulator (FDS), U.S. Nuclear Regulatory Commission, Office of Nuclear Regulatory Research (RES) and Electric Power Research Institute (EPRI), Rockville, MD, Palo Alto, CA, 2007.

[20] I S Walker, D J Wilson, M H Sherman, A comparison of the power law to quadratic formulations for air infiltration calculations, Energy Build. 27 (1998) 293-299, doi:10.1016/S0378-7788(97)00047-9.

[21] M J Hurley, D T Gottuk, J R Hall Jr., K Harada, E D Kuligowski, M Puchovsky, J Torero, J M Watts Jr., C J Wieczorek, SFPE Handbook of Fire Protection Engineering, fifth ed., Springer, 2016.

[22] S Brohez, I Caravita, Overpressure induced by fires in airtight buildings, J. Phys. Conf. (2018), doi:10.1088/1742-6596/1107/4/042031042031. 